\title{
Huge internal waves in the vicinity of the Spitsbergen Island (Barents Sea)
}

\author{
O. E. Kurkina ${ }^{1,2,3}$ and T. G. Talipova ${ }^{4}$ \\ ${ }^{1}$ Institute of Cybernetics, Tallinn University of Technology, Tallinn, Estonia \\ ${ }^{2}$ State University The Higher School of Economics, Nizhny Novgorod Branch, Nizhny Novgorod, Russia \\ ${ }^{3}$ Nizhny Novgorod State Technical University, Nizhny Novgorod, Russia \\ ${ }^{4}$ Institute of Applied Physics of Russian Academy of Sciences, Nizhny Novgorod, Russia
}

Received: 21 September 2010 - Revised: 6 January 2011 - Accepted: 7 January 2011 - Published: 25 March 2011

\begin{abstract}
The generation of huge amplitude internal waves by the barotropic tide in the Barents Sea at high latitudes is examined using the numerical model of the Euler 2-D equations for incompressible stratified fluid. The area considered is located between the Spitsbergen (Svalbard) Island and the Franz-Victoria Trough with a cross-section of $350 \mathrm{~km}$ length. There are two underwater hills about $100-150 \mathrm{~m}$ high on the background depth of about $300 \mathrm{~m}$. It is shown that intensive nonlinear internal waves with amplitudes up to $50 \mathrm{~m}$ and lengths of about $6-12 \mathrm{~km}$ are generated in this zone. The total height of such waves is huge and they must be considered as a significant factor of the environment in this basin.
\end{abstract}

\section{Introduction}

Internal waves in the shelf zones are generated mainly by tidal forcing. Very often they have huge amplitudes reaching sometimes a hundred meters and are observed over and over again everywhere in coastal zones of the World oceans (Morozov, 1985; Ostrovsky and Stepanyants, 1989; Helfrich and Melville, 2006; Vlasenko et al., 2005; Apel et al., 2007; Duda et al., 2004). Intensive internal waves generated over the shelf edge and continental slope are an important source of strong currents, vertical mixing (Babu and Rao, 2010), bottom erosion (Bogucki and Redekopp, 1999). They strongly impact on acoustic fields and significantly reduce the distance of acoustic pulse propagation (Apel et al., 2007; Warn-Varnas et al., 2009; Sridevi et al., 2010), and may be dangerous for underwater vehicles and underwater parts of oil platforms and pipelines. The prediction of underwater weather is becoming a branch of hydrometeorology now and

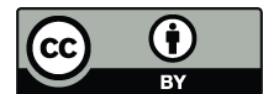

Correspondence to: O. E. Kurkina (oksana.kurkina@mail.ru) the analysis of the baroclinic disturbances periodically generated by barotropic tide over topography is the first and principal step in this problem. Detection of zones where internal waves have amplitudes large enough can be done with help of numerical modeling methods.

The modeling of tidal internal waves on various shelves of the World oceans is carried out now using numerical models of different levels (see, for example, Helfrich and Melville, 2006; Vlasenko et al., 2005; Holloway et al., 1999; WarnVarnas et al., 2005, 2010). We are focusing here on the Barents Sea, and moreover, on internal waves generated over the critical latitude $\left(74.5^{\circ} \mathrm{N}\right)$ for the semidiurnal $\left(M_{2}\right)$ tide. The critical latitude is determined as the latitude $\varphi$ where the tidal frequency equals the local inertial frequency $f=2 \Omega_{\mathrm{E}} \sin \varphi$, $\Omega_{\mathrm{E}}=0.00007292 \mathrm{~s}^{-1}$ is the frequency of the Earth's rotation. The linear theory of baroclinic tide generation predicts that there is no baroclinic wave generation over this latitude (LeBlond and Mysak, 1978). Nevertheless observations show existence of internal waves of very large amplitudes here.

We reproduce briefly the description of results (Morozov and Pisarev, 2002; Pisarev, 1996): "Special measurements of internal waves with distributed temperature sensors were carried out from drifting ice in 1983 in Saint Anna Trough and in 1986-1989 in Franz Victoria Trough. The latitude of the measurements was $80^{\circ}-81^{\circ} \mathrm{N}$ and the depths were within bounds of 200-500 m. In addition to the other phenomena, very short and localized semidiurnal internal waves were found. Their lengths were within 2-6 km. They were propagating from the slope of the trough and their amplitudes reached $40 \mathrm{~m}$. When the measuring instruments drifted from the slopes of the trough to a distance of 20-40 km toward flat bottom regions, the amplitude of these waves significantly decreased. Under certain stipulations, these semidiurnal waves were classified as internal tides.".

Published by Copernicus Publications on behalf of the European Geosciences Union. 


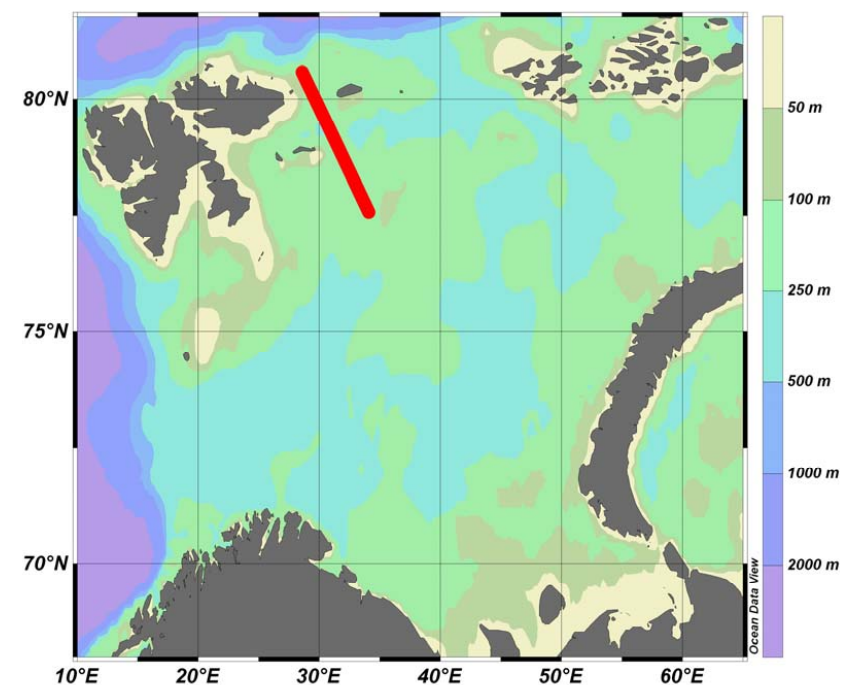

Fig. 1. Area map with the cross-section (red strip) between the points $34.11^{\circ} \mathrm{E}, 77.57^{\circ} \mathrm{N}$ and $28.61^{\circ} \mathrm{E}, 80.58^{\circ} \mathrm{N}$.

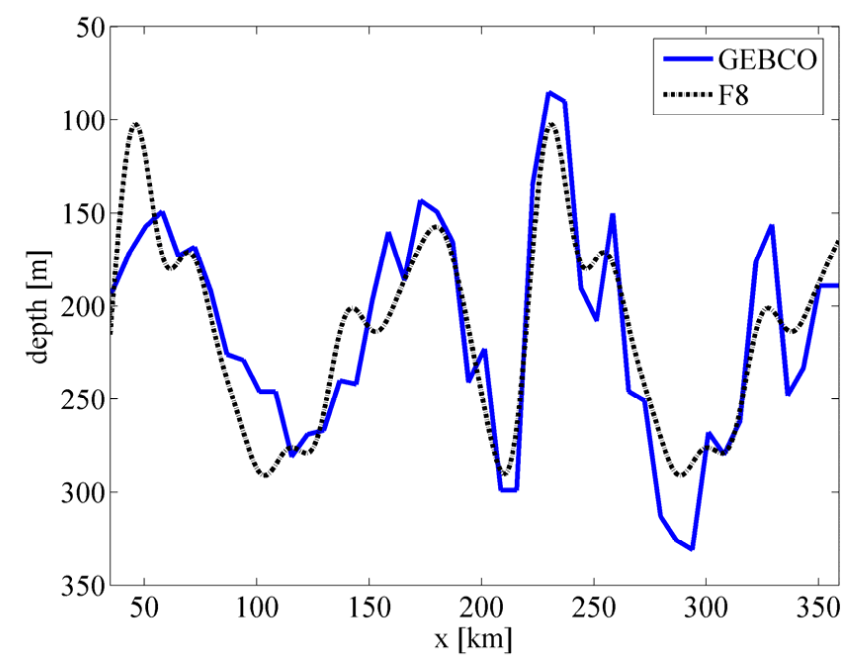

Fig. 2. Bottom relief of the area cross-section shown in Fig. 1 (blue line is GEBCO, dotted line is the spline).

The possibility of the generation of internal tidal waves by topography above the critical latitude was shown by Nakamura et al. (2000), with the use of the fully nonlinear nonhydrostatic model. These waves are generated and trapped by the barotropic tidal flux at the lee side of the sill. They were called unsteady lee waves and their amplitudes depend on the amplitude of the tidal flow speed and steepness of the bottom topography. Vlasenko et al. (2003) were the first who modeled the nonlinear generation of internal waves near and over the critical latitude in the Barents Sea near Bear Island and found propagated short nonlinear internal waves with amplitudes about $20 \mathrm{~m}$.

The aim of this paper is to explain the nature of large amplitude internal waves observed over the critical latitude
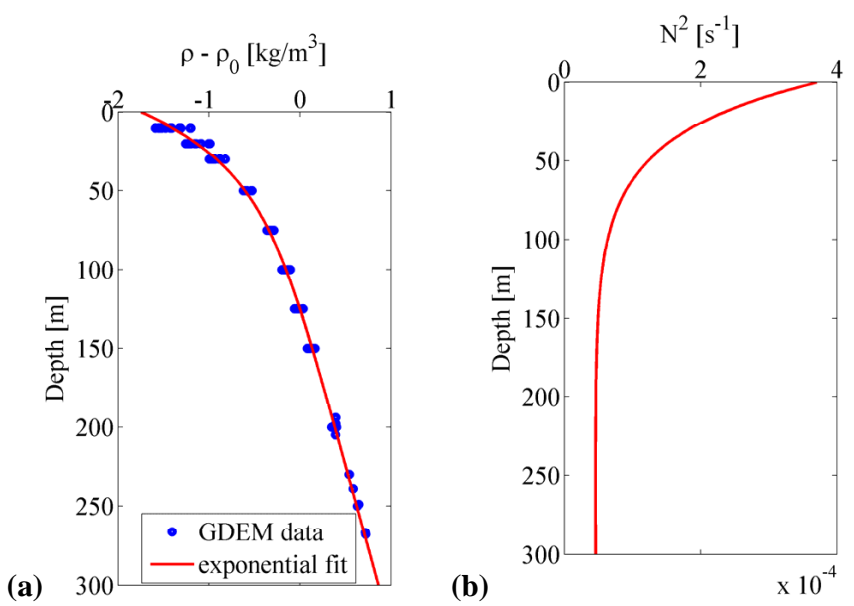

Fig. 3. The typical vertical density profile (a) in the studied area and the Brunt-Väisälä frequency (b) taken from the Database GDEM for July.

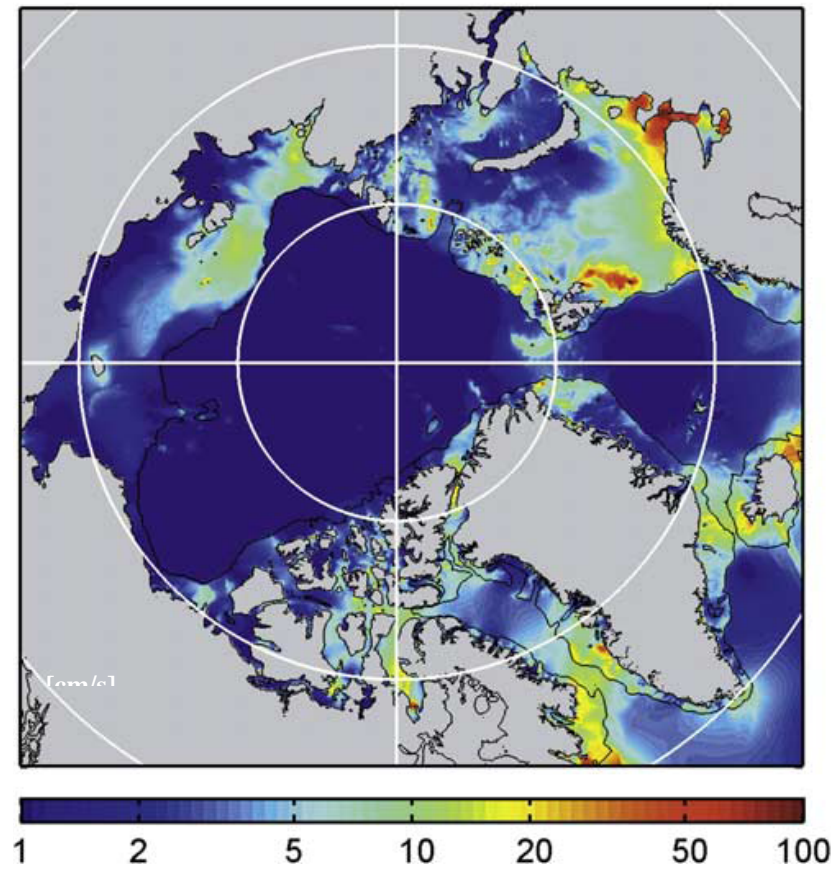

Fig. 4. The mean tidal current speed $\left(\mathrm{cm} \mathrm{s}^{-1}\right)$ based on the simulation of 14 days of hourly total tidal speed from the 8-constituent inverse solution AOTIM.

(mainly in the Franz Victoria Trough), using the numerical results within the framework of fully nonlinear Euler equations for stratified water, their features and to carry out the forecast of dangerous underwater events for this region. The paper is organized as following: the numerical model is briefly described in Sect. 2, model input is discussed in Sect. 3 and in Sect. 4 the results of the numerical modeling are presented. They are discussed in Sect. 5. 

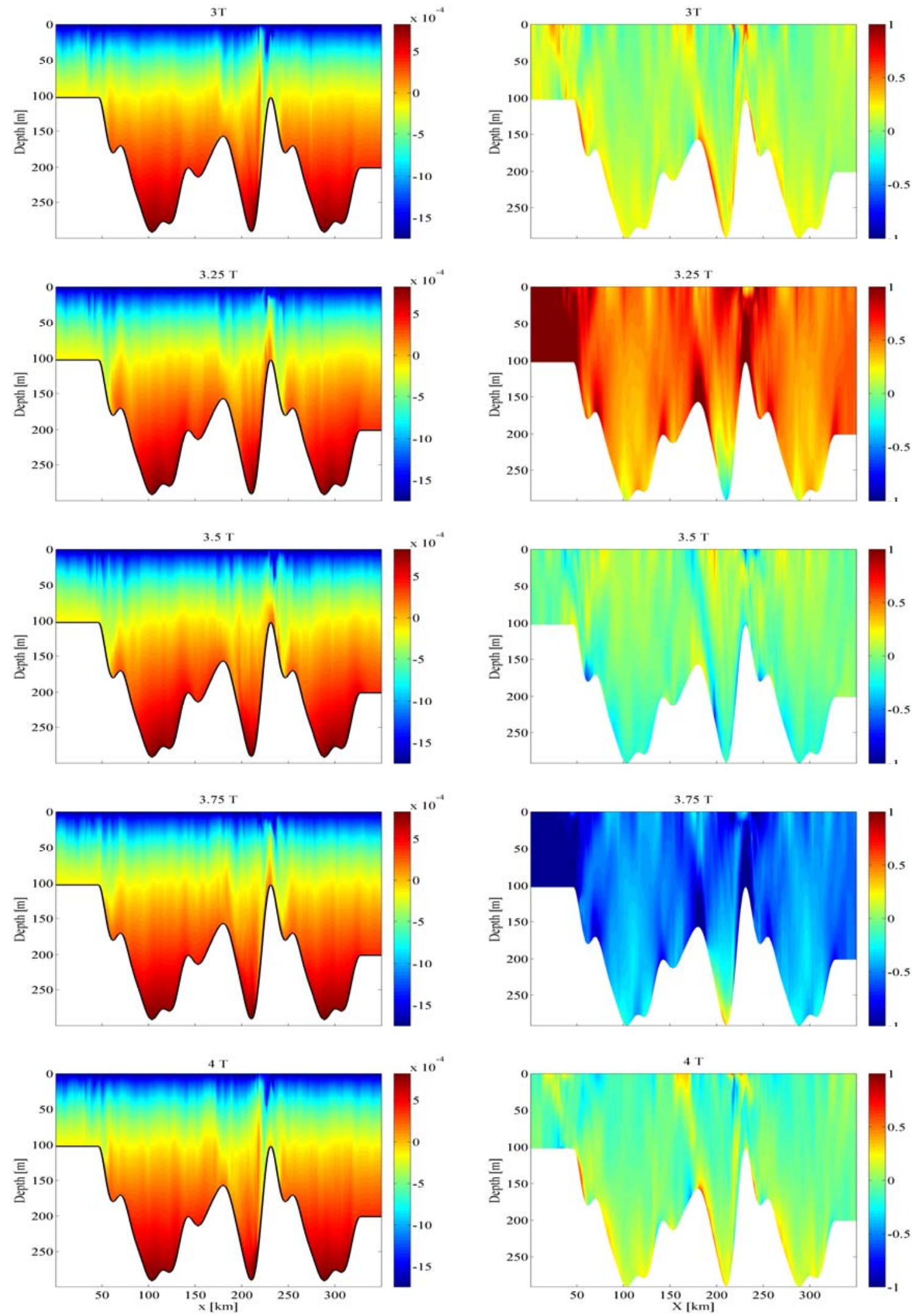

Fig. 5. Snapshots of the normalized density (left panel) and horizontal velocity (in $\mathrm{m} \mathrm{s}^{-1}$ ) (right panel). 


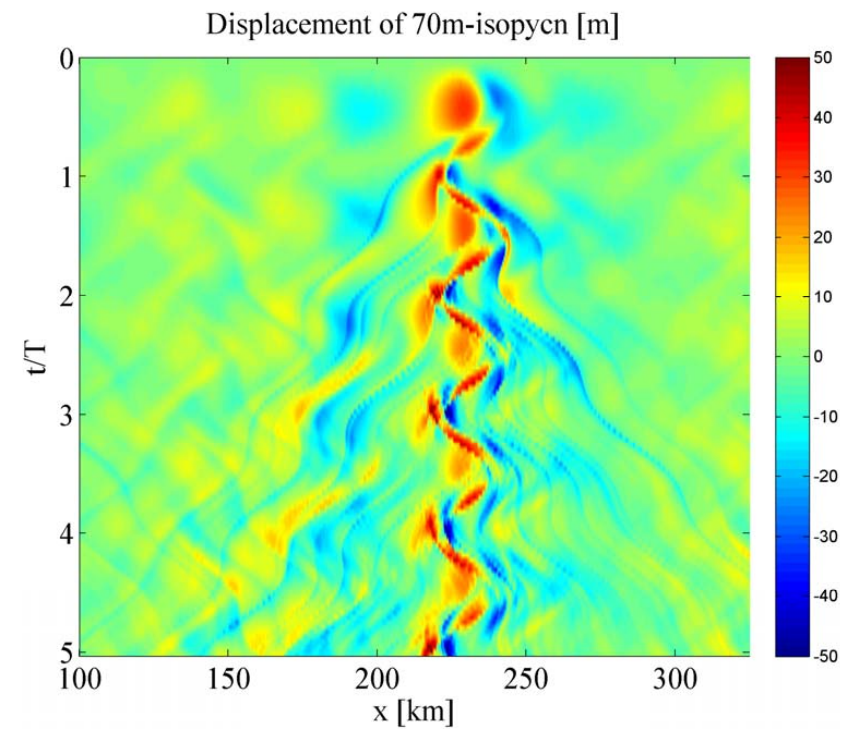

Fig. 6. The Hovmuller plot for the displacement of the isopycn located at $70 \mathrm{~m}$ depth in the undisturbed state.

\section{Numerical model}

The Lamb (1994) model is taken for simulating the generation and propagation of internal waves in the Barents Sea. The model equations are the two-dimensional (vertical section) inviscid, incompressible Boussinesq equations on a rotating f-plane. The coordinates are defined as follows: $x$ is along a section, $y$ is perpendicular to section, and $z$ is the depth. The equations of the model are

$$
\begin{aligned}
& \boldsymbol{V}_{t}+(\boldsymbol{V} \nabla) \boldsymbol{V}-f \boldsymbol{V} \times \boldsymbol{k}=-\nabla P-\boldsymbol{k} \rho g \\
& \rho_{t}+\boldsymbol{V} \nabla \rho=0
\end{aligned}
$$

$$
\nabla \boldsymbol{V}=0
$$

where $\boldsymbol{V}(u, v, w)$ is the velocity vector, $\nabla$ is the threedimensional vector gradient operator, subscript $t$ denotes the time derivative, $\rho$ is the density, $P$ is the pressure, $g$ is the gravitational acceleration, $f$ is the Coriolis parameter taken as $1.425 \times 10^{-4} \mathrm{~s}^{-1}$ for the latitude of 78.5 degrees, and $\boldsymbol{k}$ is the unit vector along the z-direction. The normal to the section velocity is included in the model, but no variation with coordinate $y$ is allowed. So, in the three-dimensional Eqs. (2)-(4) the partial derivatives with respect to $y$ are neglected, i.e., $\frac{\partial}{\partial y}()=0$.

The equations are transformed to the following terrain coordinate system (sigma-coordinates) which leads to higher vertical resolution over the bank regions. The equations are solved over a domain bounded by the topography below and a rigid lid above. The flow is forced by specifying a semidiurnal tidal inflow at the left boundary of the form $V_{T} \sin (\omega t)$ where $\omega$ is the $M_{2}$ tidal frequency assumed to have a 12.4-h period $(T)$. The value $V_{T}$ is discussed below. On the right boundary an outflow condition is used. The initial conditions comprise the undisturbed equilibrium state with uniform horizontal density.. The horizontal grid size is $90 \mathrm{~m}$, and the vertical sigma-coordinate resolution consists of 80 grid points. The time step is tied to the Courant-Levi condition and varies from $2 \mathrm{~s}$ to $5 \mathrm{~s}$.

\section{Input for the modeling}

For the modeling we chose the cross-section close to the Franz Victoria Trough in the Barents Sea shown on Fig. 1. It starts from point $34.11^{\circ} \mathrm{E}, 77.57^{\circ} \mathrm{N}$ and finishes at point $28.61^{\circ} \mathrm{E}, 80.58^{\circ} \mathrm{N}$. A whole wave path lays over the critical latitude $\left(74.5^{\circ} \mathrm{N}\right)$. The bathymetry along this cross-section taken from GEBCO is marked in Fig. 2 by the blue line. It is splined for the purpose of modeling by 8 Fourier components for a better description of the middle portion of the domain as

$H(x)=a_{0}+\sum_{m=1}^{8}\left(a_{m} \cos (m \kappa x)+b_{m} \sin (m \kappa x)\right)$

where $\kappa=0.03398 \mathrm{~m}^{-1}$ and $a_{m}$ and $b_{m}$ are the Fourier coefficients. The approximation is shown in Fig. 2 by the dotted line. Typical vertical density profile in this area is taken from GDEM climatology for July. It is fitted by the exponential functions

$\rho=1000+q_{1} \exp \left(r_{1} z\right)+q_{2} \exp \left(r_{2} z\right)$

$\left(q_{1}=27.93 ; r_{1}=1.64 \times 10^{-4} ; q_{2}=-1.2 ; r_{2}=-2.844 \times\right.$ $10^{-2}$ ) and the Brunt-Väisälä frequency $N(z)$ is calculated, both $\rho(z)-\rho_{0}\left(\rho_{0}\right.$ is $\left.1027.48 \mathrm{~kg} \mathrm{~m}^{-3}\right)$ and $N(z)$ are shown in Fig. 3.

The region in question is characterized by strong tidal currents and underwater mount ridges. The map of the mean tidal velocities in the Arctic Ocean (with the 8 tidal components) calculated with the help of the Arctic Ocean Tidal Inverse Model (AOTIM) is presented in Padman and Erofeeva (2004) and represented in Fig. 4. A logarithmic color scale is used to resolve speed variability in both weak and energetic regions. It is mentioned that four tidal components $M_{2}, S_{2}, K_{1}$ H $O_{1}$ contain up to $79 \%, 10 \%, 5 \%$ H $1 \%$ of total (8-components) potential energy of the tide, respectively. So the semi-diurnal tide $M_{2}$ dominates in the variability of tidal velocities in Arctic Ocean.

The largest mean values of the tidal velocities approaches $100 \mathrm{~cm} \mathrm{~s}^{-1}$ in the southern Barents Sea near the entrance to the White Sea and around Bear Island in the western Barents Sea south of Svalbard. The maximal velocities exceed the mentioned values of the mean velocities as much as twice, at least.

The barotropic tidal wave is presented only by the semidiurnal tide, and taking into account that the mean tidal current in the studied area is about $50 \mathrm{~cm} \mathrm{~s}^{-1}$, the maximal barotropic tidal velocity constitutes $1 \mathrm{~m} \mathrm{~s}^{-1}$, and we use this value for $V_{T}$ to setup the model. 

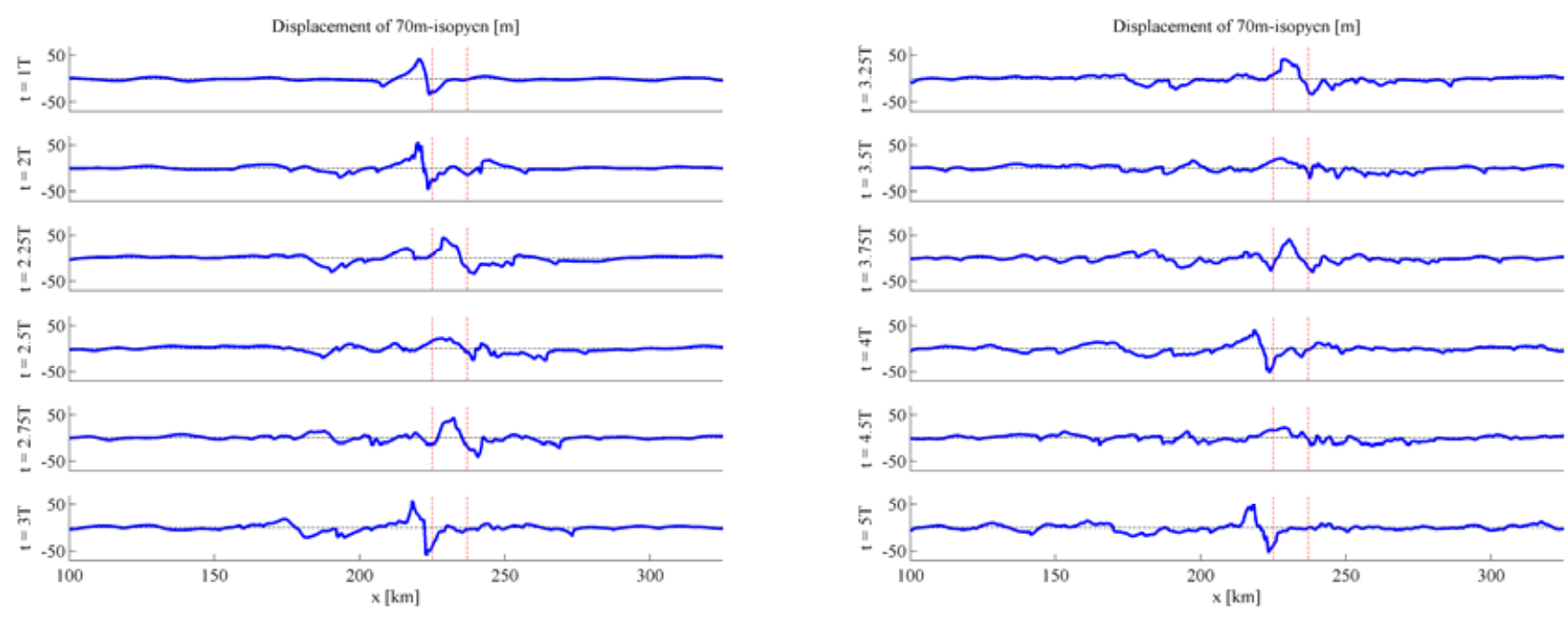

Fig. 7. Displacement of $70 \mathrm{~m}$ isopycn for different times.

\section{Results of the modeling}

The calculated density fields (left) and total (barotropic and baroclinic) horizontal velocity values (right) are shown in Fig. 5 for various tidal phases. Normalized density $(\rho-$ $\left.\rho_{0}\right) / 1000$ is given, where $\rho$ is sea water density $\left[\mathrm{kg} \mathrm{m}^{-3}\right]$. In the book by Valsenko et al. (2005) it was mentioned that the full periodicity of the process is formed after $2-3 T$ ( $T$ is tidal period for $M_{2}$ ).

The time moment $3 T$ corresponds to the ending of the ebb phase and starting of the flood phase. The velocity of the tide at this moment is zero and there are large displacements of isopycnes over the left side of the largest hill. The more intensive internal waves are generated on the slopes of the highest central hill (between 200 and $300 \mathrm{~km}$ with the crest at $230 \mathrm{~km}$ ); their amplitudes decreases when they propagate out of this zone.

After a quarter of the tidal period $(t=3.25 T)$, the maximum of the tidal phase comes; velocities reach their maximums, the zone of generation moves to the right lee slope of the central hill. At the time moment $t=3.5 T$ the phase of the tide finishes and the tide velocity vanishes; internal waves are developed well on the right side of the central hill. When the ebb is maximal (at $t=3.75 T$ ) the zone of generation is also shifted to another (left) lee side of the hill and the waves become maximal at time $t=4 T$ when the velocity of the tide vanishes. So, the internal waves generated are mainly the unsteady lee waves generated by the tide and ebb currents near the lee slope of the hill with the phase shift of about quarter of the tidal period between the maximal tide velocity and maximal isopycnal displacement. The wave velocities are evident at the time moments $3 T, 3.5 T$ and $4 T$, when the tidal current is zero, and their values do not exceed $0.4 \mathrm{~m} \mathrm{~s}^{-1}$. The process is well illustrated in the Hovmuller plot (or $x-t$ diagram) for displacement of the isopycn located at $70 \mathrm{~m}$ depth

in the undisturbed state (Fig. 6). The more intensive internal waves with amplitudes of $50 \mathrm{~m}$ and total heights (crestto-trough height) of about $80 \mathrm{~m}$ appear regularly in the strip of about $40 \mathrm{~km}$ width and central position approximately at $230 \mathrm{~km}$. Their length may be evaluated using displacements presented in Fig. 7; they are about $6-12 \mathrm{~km}$ long. The typical periods of the modeled waves are $0.2-0.35 T$.

In the book by Vlasenko et al. (2005), the classification of the processes of internal wave generation is suggested. The classification is based on the magnitude of the Froude number, $F r=u_{\max } / C_{\mathrm{ph}}$, where $u_{\max }$ is maximal velocity of the barotropic tidal flow in the $x$-cross-section $\left(u_{\max }=V_{T} H\left(x_{0}\right) / H(x)\right)$ and $C_{\mathrm{ph}}$ is the phase speed of long internal waves. It is calculated from the eigenvalue problem numerically (Grimshaw et al., 2002; Holloway et al., 1997). It was stated that when $F r>1$, a generation of strong nonlinear internal lee waves by tide is possible at any latitude, whereas there is no internal wave generation when $F r \ll 1$ above the critical latitude. So the conclusion that the waves shown in Figs. 5, 6, and 7 are the internal lee waves should be drawn.

Spatial variation of the Froude number along the studied section is shown in Fig. 8 together with other characteristic quantities: phase speed of internal waves, maximal tidal velocity, and depth of the defined area of the Sea. The zone where the Froude number is greater than 1 lies between the points $225 \mathrm{~km}$ and $237 \mathrm{~km}$; there the intensive internal waves were discovered.

\section{Conclusions}

The possibility of generation of strong nonlinear unsteady lee internal waves by the barotropic tide in the Barents Sea above the critical latitude has been demonstrated through numerical simulation. The chosen area for the modeling was 

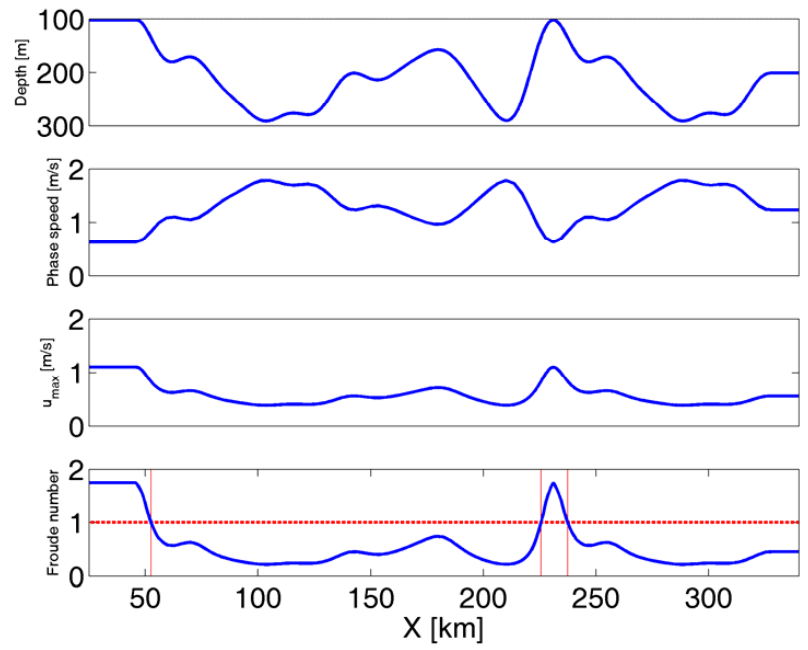

Fig. 8. The Froude number and other characteristic quantities against the distance at the defined area of the Sea.

close to the Franz Victoria Trough; the parameters of the calculated internal waves in the chosen region agree qualitatively to those observed in the Trough. The modeled waves had the same amplitudes as the observed ones, $40 \mathrm{~m}$, and the close wavelengths, $6-12 \mathrm{~km}$. They preserved significant amplitudes of isopycn displacements at a distance of $20 \mathrm{~km}$ from the zone of generation. They appeared two times per semidiurnal tide period and live about $6.2 \mathrm{~h}$ slowly propagating out of the peak of the underwater hill. More intensive waves were generated in the ebb phase and at the end of the ebb phase, when the ebb velocity vanished. The largest observed drop between the crest and trough was about $80 \mathrm{~m}$; it appeared at the end of the ebb phase each $12.4 \mathrm{~h}$.

Acknowledgements. This work was supported by grants RFBR 10-05-00199 and Grant of President of RF for young researchers MK-846.2009.1 (O.K.) and RFBR 09-05-00204 and 09-05-90408 (T.T.).

Edited by: E. Pelinovsky

Reviewed by: two anonymous referees

\section{References}

Apel, J., Ostrovsky, L. A., Stepanyants, Y. A., and Lynch, J. F.: Internal solitons in the ocean and their effect on underwater sound, J. Acoust. Soc. Am., 121, 695-722, 2007.

Babu, S. V. and Rao, A. D.: Mixing in the surface layers in association with internal waves during winter in the northwestern Bay of Bengal, Nat. Hazards, in press, doi:10.1007/s11069-010-9607-5, 2010.

Bogucki, D. J. and Redekopp, L. G.: A Mechanism for sediment resuspension by internal solitary waves, Geophys. Res. Lett., 26, 1317-1320, 1999.
Duda, T. F., Lynch, J. F., Irish, J. D., Beardsley, R. C., Ramp, S. R., Chiu, C.-S., Tang, T. Y., and Yang, Y.-J.: Internal tide and nonlinear internal wave behavior at the continental slope in the northern south China Sea, IEEE J. Oceanic Eng., 29, 1105-1130, 2004.

Grimshaw, R., Pelinovsky, E., and Poloukhina, O.: Higher-order Korteweg-de Vries models for internal solitary waves in a stratified shear flow with a free surface, Nonlin. Processes Geophys., 9, 221-235, doi:10.5194/npg-9-221-2002, 2002.

Helfrich, K. R. and Melville, W. K.: Long nonlinear internal waves, Annu. Rev. Fluid Mech., 38, 395-425, 2006.

Holloway, P., Pelinovsky, E., Talipova, T., and Barnes, B.: A nonlinear model of internal tide transformation on the Australian North West Shelf, J. Phys. Oceanogr., 27(6), 871-896, 1997.

Holloway, P., Pelinovsky, E., and Talipova, T.: A generalized Korteweg-de Vries model of internal tide transformation in the coastal zone, J. Geophys. Res., 104(C8), 18333-18350, 1999.

Lamb, K.: Numerical experiments of internal wave generation by strong tidal flow across a finite amplitude bank edge, J. Geophys Res., 99(C1), 848-864, 1994.

LeBlond, P. H. and Mysak, L. A.: Waves in the Ocean, Elsevier, Amsterdam, 602 p., 1978.

Morozov, E. G.: Ocean Internal Waves, Nauka, Moscow, 1985 (in Russian).

Morozov, E. G. and Pisarev, S. V.: Internal Tides at the Arctic Latitudes (Numerical Experiments), Oceanology, 42, 153-161, 2002.

Nakamura, T., Awaji, T., Hatayama, T., Akimoto, K., Takizawa, T., Koho, T., Kawasaki, Y., and Fukasava, M.: The generation of large-amplitude unsteady lee waves by subinertial tidal flow: a possible vertical mixing mechanism in the Kuril Straits, J. Phys. Oceanogr., 30, 1601-1621, 2000.

Ostrovsky, L. and Stepanyants, Yu.: Do internal solitons exist in the ocean?, Rev. Geophys., 27, 293-310, 1989.

Padman, L. and Erofeeva, S.: A barotropic inverse tidal model for the Arctic Ocean, Geophys. Res. Lett., 31, L02303, doi:10.1029/2003GL019003, 2004.

Pisarev, S. V.: Low-Frequency Internal Waves Near the Shelf Edge of the Arctic Basin, Oceanology, 36, 771-778, 1996.

Sridevi, B., Murty, T. V. R., Sadhuram, Y., and Murty, V. S. N.: Impact of internal waves on the acoustic field at a coastal station off Paradeep, east coast of India, Nat. Hazards, in press, doi:10.1007/s11069-010-9567-9, 2010.

Vlasenko, V., Stashchuk, N., Hutter, K., and Sabinin, K.: Nonlinear internal waves forced by tides near the critical latitude, Deep-Sea Res. Pt. I, 50, 317-338, 2003.

Vlasenko, V., Stashchuk, N., and Hitter, K.: Baroclinic tides, Cambridge Univ. Press, Cambridge, 2005.

Warn-Varnas, A. C., Chin-Bing, S. A., King, D. B., Hawkins, J. A., Lamb, K. G., and Teixeira, M.: Yellow Sea ocean-acoustic solitary wave modeling studies, J. Geophys. Res., 110, C08001, doi:10.1029/2004JC002801, 2005.

Warn-Varnas, A., Chin-Bing, S. A., King, D. B., Hawkins, J., and Lamb, K.: Effects on acoustics caused by ocean solitons, Parts A,B, Nonlinear Anal.-Theor., 71, e1807-e1817, e2194-e2204, 2009.

Warn-Varnas, A., Hawkins, J., Lamb, K. G., Piacsek, S., Chin-Bing, S., King, D., and Burgos, G.: Solitary wave generation dynamics at Luzon Strait, Ocean Model., 31, 9-27, 2010. 